\title{
Bilateral Stereotaxic Lesions in the Management of Parkinsonism and the Dyskinesias
}

\author{
F. JOHN GILLINGHAM,* M.B.E., M.B., F.R.C.S., F.R.C.S.ED. ; \\ S. KALYANARAMAN, $\dagger$ PH.D., M.S., F.R.C.S., F.R.C.S.ED., F.I.C.S.; A. A. DONALDSON, $\ddagger$ L.R.C.P.\&S.ED., D.M.R.D.
}

Brit. med. F., 1964, 2, 656-659

Since the establishment of stereotaxic surgery as a therapeutic procedure of value in the management of Parkinsonism and the dyskinesias, most centres specializing in this operation have carried it out bilaterally in some of their patients. However, bilateral stereotaxic surgery has been associated with a certain amount of hazard, somewhat greater than in the case of unilateral operations. There has been a general reluctance to subject these patients to operation on both hemispheres, and the criteria for selection for surgery have been more strictly applied before the second procedure.

\section{Previous Reports}

In contrast to the very large number of papers dealing with unilateral stereotaxic operations and their results, published reports analysing the problems of bilateral operations have been few. Wycis and Spiegel (1958) reported nine cases of bilateral pallido-ansotomy. Broager and Norhølm (1961) referred to 37 cases treated bilaterally in a series of 100 consecutive patients. Krayenbühl, Wyss, and Yasargil (1961) published a detailed analysis of 51 bilateral stereotaxic procedures. Krayenbühl, Siegfried, and Yasargil (1963) subsequently published a long-term follow-up of these patients. Cooper and Riklan (1962) referred briefly to 200 patients bilaterally treated. Bertrand and Martinez (1962) reported 28 who underwent bilateral operations. Gros, Serrats, AdibYazdi, and Parker (1963) reported on a series of 41 cases. Markham and Rand (1963) discussed 35 patients subjected to bilateral procedures. Gillingham and Kalyanaraman (1963) analysed the results of 64 bilateral operations.

\section{Present Series}

This report deals in a more detailed manner with a slightly larger series. Eighty-three patients in a group of 344 have been treated by us by bilateral stereotaxic operations over the seven-year period from 1957, although unilateral operations were begun in 1955. Eight of these patients suffered from dyskinesias. Their analysis by age at the time of the second operation is given in Table I.

TABLE I.-Age Incidence of Patients Treated by Bilateral Stereotaxic

\begin{tabular}{|c|c|c|c|c|c|c|c|}
\hline Age-group: & $<10$ & $10-19$ & $20-29$ & $30-39$ & $40-49$ & $50-59$ & $60-69$ \\
\hline $\begin{array}{c}\text { No. with Parkinsonism } \\
,, \text {, dyskinesias }\end{array}$ & $\overrightarrow{1}$ & $\overline{2}$ & $\overline{2}$ & $\begin{array}{l}4 \\
2\end{array}$ & $\begin{array}{r}19 \\
1\end{array}$ & 35 & 17 \\
\hline
\end{tabular}

More than half of the total number required constant help for their daily personal routine before operation. Five of these patients were ambulant for only part of the day and

* Professor of Surgical Neurology, University of Edinburgh.

+ Commonwealth Scholar, Department of Surgical Neurology, University of Edinburgh.

$\ddagger$ Neuroradiologist, Department of Surgical Neurology, University of Edinburgh. required part-time nursing care. Only three were doing their full work at the time of the first operation.

All patients with Parkinsonism suffered from rigidity to a greater or less degree. All had tremor except one. In each case the symptoms were bilateral. Only four were free from additional disabilities like oculogyric crises (12 cases), festination (29 cases), speech difficulties (65 cases), excessive salivation ( 40 cases), pain ( 22 cases), or autonomic phenomena.

\section{Operative Procedure}

The stereotaxic procedure followed that of Guiot and has been reported in detail from this department (Gillingham, Watson, Donaldson, and Naughton, 1960 ; Donaldson and Gillingham, 1960 ; Gillingham, 1961, 1962). . The approach was occipital, penetrating the thalamus and crossing the internal capsule to reach the pallidum, lesions varying between 12 and $17 \mathrm{~mm}$. from the midline.

\section{Radiological Alignment}

In nearly all cases, because of the accuracy of the technique, it was possible to replace the stereotaxic frame into the recessed screws left in the outer table of the skull from the first operation. Preliminary plain films of the skull, with standard technique, permitted comparison with previous postoperative films. The position of the stainless-steel marker at the site of the original coagulation was checked, and if it had not moved it was used as a target point for aligning the sights of the stereotaxic frame for the second operation. In many cases (probably in about half the number) the marker was found to have moved somewhat from its original position, usually in a downwards and backwards direction. This was thought to be due to the marker sinking under gravity in the necrotic lesion produced by coagulation. In these cases a cannula or catheter was reinserted into the ventricular system and the anterior commissure was outlined with Myodil (iophendylate) injected through the catheter. The sights were then aligned under fluoroscopic control in the same manner as at the first operation (Donaldson and Gillingham, 1960).

\section{Sites of Lesions}

Charts of the electrocoagulation lesions from post-operative radiographs were made in all cases on the stereotaxic atlas of Schaltenbrand and Bailey (1959). The sites of these lesions were further confirmed by operative biopsies in 13 cases, depth electrical recording in five cases, and necropsy studies in three. Seventy-eight of these patients had at least some involvement of the posterior limb of the internal capsule and 15 had planned bilateral transcapsular lesions. We found no greater post-operative morbidity in making the so-called mirror lesions, although other authors, notably Hassler, 
Riechert, Mundinger, Umbach, and Ganglberger (1960) caution against this.

Detailed follow-up studies were carried out in all the patients. Two-thirds have been observed for more than two years and one-third for more than three years after operation on the other hemisphere.

A large lesion did not necessarily mean that it was effective. The first essential to success was strategic siting of the lesion. The targets chosen were the ventro-lateral nucleus of the thalamus, the posterior limb of the internal capsule, or the globus pallidus. Some formed a combination of all three. It was our aim to interrupt the ansa and fasciculus lenticularis as strategically and completely as possible. Certainly it would appear that an adequate lesion at one or other of these sites or an elongated lesion through the capsule would achieve a good result. In general, thalamo-capsular lesions gave the best result for tremor and pallido-capsular lesions for rigidity.

The bigger the lesion, irrespective of its site in the basal ganglia or the capsule, the greater were the chances of postoperative complications and neurological deficits. With small lesions ( 7 by 5 by $5 \mathrm{~mm}$.) permanent neurological deficits were minimal.

\section{Mortality and Morbidity}

There were no immediate post-operative deaths. Late postoperative mortality (between three months and a year after the second operation) occurred in five in this series. In three of these cases the operative result was good and death was due to intercurrent chest infection, coronary thrombosis, and carcinoma of the stomach respectively. In one death was indirectly attributable to progress of disease, and in the last (one of the early cases) it was due to a poorly placed lesion with intraventricular haemorrhage.

Major post-operative complications were rare. There were no cases of dense or prolonged hemiparesis or sensory changes, hemianopia, large intracranial haemorrhage, or pulmonary embolism in this series. Minor haemorrhage (diagnosed by a shift in the position of the steel marker in the $x$-ray film after operation associated with extreme drowsiness) at the site of the lesion occurred in two cases. One of these patients died after a few months, and the other recovered fully in a few days.

\section{Post-operative Hemiballismus}

This interesting complication occurred in $3(3.6 \%)$ out of 83 bilateral cases after the second-hemisphere operation. In all three cases it was temporary and was associated with an excellent operative result on long-term follow-up. It is interesting to note that hemiballismus occurred in only $1(0.3 \%)$ out of 344 patients with unilateral operation. This relatively greater incidence of hemiballismus after bilateral surgery was also reported by Dierssen, Gioino, and Cooper (1961), their figures being $4 \%$ and $10 \%$ for the unilateral and bilateral operations respectively. Three cases are too few for any conclusions to be drawn, but it is interesting to note that the time intervals between the two operations in these three patients were one, two, and five months respectively (probably because they were aged 51 or less) and that in all three the second operation was performed on the dominant side. These features may be merely coincidental.

\section{Degree of Rehabilitation Achieved}

Of the 83 cases 72 with Parkinson's disease and seven with dyskinesia were discharged from hospital to an independent life or to suitably protected circumstances. The other four required permanent institutional care because of the advanced and progressive nature of their affliction.

\section{Effects on Parkinsonism}

Rigidity.-This was considerably reduced. In 29 patients it was abolished in all four limbs, and in 28 it was very much improved. Fifteen patients, however, had only moderate improvement in rigidity, and in three it was unaffected or only slightly reduced. Pain associated with rigidity was almost always relieved by surgery.

Tremor.-This was equally amenable to surgery. It was abolished in all four limbs in 22 cases and very much improved in 35. Moderate improvement only was seen in 15 patients and only slight improvement was visible in two.

At present in almost every case a standard double ipsilateral lesion (thalamo-capsular and pallido-capsular) is made. In some of the earlier cases, however, only a thalamic or pallidal lesion was made on one or both sides. We feel that the results reported above would have been better if in the entire series double ipsilateral lesions had been made in both hemispheres. It is of interest to note that Cassinari, Pagni, Cabrini, and Pauli (1963) reported 26 patients in whom they felt that simultaneous thalamo-pallidolysis was superior to a thalamic or pallidal lesion alone in controlling tremor and rigidity.

Handwriting.-In all patients with Parkinsonism in this series, handwriting was more or less affected, in 63 of them severely so. Despite post-operative reduction of tone to normal levels, handwriting improved only slightly. This was in contrast with the dyskinesias, when surgical abolition of involuntary movements in the hand was always associated with a great improvement in handwriting.

Oculogyric Crises.-Contrary to earlier reports from this department and the results reported by most authors, we were pleasantly surprised to find on a long-term follow-up that bilateral stereotaxic surgery favourably influenced oculogyric crises. In this series 12 patients had this complication preoperatively. In six of them crises were fully abolished after the second operation and in four they were very much reduced in frequency and severity. In one case they were unaffected. In one patient the attacks ceased spontaneously a few months before the first operation. It should also be recorded that one patient developed inability of voluntary conjugate deviation of the eyes two years after bilateral stereotaxy. The effect of stereotaxic surgery on oculogyric crises will be reported in detail separately.

Festination.-This was occasionally improved but rarely eliminated.

Salivation.-Salivation and other autonomic manifestations were sometimes helped, and they were certainly more easily managed by medical treatment after surgery than before.

\section{Post-operative Measures}

Almost always, patients needed less medication after operation. It is dangerous, however, in these advanced cases of Parkinsonism to stop or reduce drugs suddenly after operation. Two patients were thus precipitated into an acute Parkinsonian crisis and needed urgent in-patient care.

Within broad limits the greater the intellectual and emotional reserve of the patient before surgery the fuller was the benefit obtained by surgical intervention. Thus the presence of poor initiative, confusion, and intellectual deterioration formed a serious contraindication to surgical treatment and especially to bilateral surgery if it was markedly increased after the first procedure. An abnormal electroencephalogram was often helpful as confirmatory evidence against surgery in such cases. 


\section{Time Interval Between the Two Operations}

The time interval between operations on the two sides varied between 2 and 36 months, usually depending on the speed of recovery from the first operation as well as the severity and progress of disease on the second side. Even in well-preserved patients we feel that bilateral procedures should not be carried out at the same time for fear of reducing intellectual performance, particularly with regard to recent memory. Each case must be judged on its merits, but in general an interval of at least two to three months would appear to be wise.

\section{Effect of Bilateral Surgery on Speech}

The main risks of operation on the second hemisphere were its effects on speech. Krayenbühl et al. (1961) reported deterioration of speech in 7 out of 23 bilateral thalamotomies and in 17 out of 28 cases with pallidal lesion on one side and thalamic lesion on the other. Krayenbühl et al. (1963) in a long-term follow-up of bilateral cases reported aggravation of speech difficulties in $60 \%$ of cases, with post-operative aphonia in $13 \%$. Meyers (1963) found reduction in voice volume and central dysarthria in two-thirds of patients with bilateral lesions in Forel's tegmental field. Cooper (1961) reported the incidence of temporary and permanent speech difficulties after unilateral surgery as $1 \%$ and $10 \%$ respectively. In bilateral surgery these figures increased to $6 \%$ and $18 \%$. Approximately one-fifth of his patients had dysphasia, which was not included in the figures of the other authors quoted above. On the other hand, Gros et al. (1963) and Wycis (1963) did not feel that speech disturbances occurred to a greater degree after second-hemisphere surgery. The numbers of cases studied by them, however, were relatively small.

In conformity with the findings of many authors speech was improved in the present series if the pre-operative deficit was mainly due to rigidity of chest, jaw, and tongue. However, further reduction of voice volume occurred in patients in whom it was already poor. Of the 75 patients with Parkinsonism treated by us this complication occurred in 27. Of these, 21 had some reduction of voice volume before the second operation, usually following the first operation. Reduction of voice volume after the first operation would therefore be a relative contraindication for the second.

A similar situation applied to the presence of dysarthria. Of 25 patients who had severe and permanent slurring after the second operation, 13 had some before or after the first operation.

Most of the lesions involved both the capsule and the thalamus. It was difficult to determine whether damage to either or both was the factor in the production of these complications. Krayenbühl et al. (1961) implicated the thalamus and pallidum in similar situations. Guiot (1961) and Penfield (personal communication, 1963) implicated the thalamus. Bertrand and Martinez (1962) implicated the capsule. Study of the lesions created after depth electrical recording in association with the results of stimulation during surgery might provide the final answer to this problem.

\section{Psychological and Intellectual Deterioration}

Although gross pre-operative psychological and intellectual deficits contraindicated operation on the other hemisphere, these complications tended to occur after bilateral surgery in a small proportion of patients declared to be within normal range after the first operation, or only slightly deteriorated. Precipitation of mental depression associated with some return of tremor and festination was noted in nine cases after the second operation.
Fortunately, in six of these it responded very well to Tofranil (imipramine) or Tryptizol (amitriptyline), which restored the patient to his satisfactory pre-operative state.

Intellectual or emotional deterioration was noted in six patients. Four of these were affected moderately severely before operation (early cases in the series), and it was aggravated after surgery on the second side. The other two, however, had no such pre-operative deficit. In one of these the lesions were thought to be too large and in the other the operation on the second hemisphere was carried out too soon after the first operation (six weeks). Spiegel and Wycis (1962a) suggest that bilateral lesions affecting the nucleus ventralis anterior also interrupt fibre systems connecting the dorso-medial nuclei with the frontal lobe (since these fibres pass through this nucleus) and a psychic syndrome similar to that following bilateral thalamo-frontal interruption may ensue. We did not encounter such a case in our series probably because our lesions were smaller than those of others who met with this complication.

It should be noted that in the last consecutive 30 cases of this series none of these complications occurred.

\section{Effect of Second Operation on the Previously Treated Side}

As has been noted by other authors, it was often seen that surgery on one side improved symptoms temporarily on the ipsilateral side by $15-25 \%$ in addition to benefiting the contralateral side. Slight return of tremor at the second operation to the previously treated limbs sometimes worried the perfectionist type of patient, but it usually settled down again and did not in fact constitute much practical difficulty. This phenomenon was of considerable interest and has been noted by other authors (Bertrand and Martinez, 1962 ; French, Story, Galicich, and Schultz, 1962 ; Spiegel and Wycis, 1962b.)

\section{Multiple Operations}

Emphasis was placed throughout on conservative lesions in treating the second side. It was felt that a third operation, adding a further small lesion after a suitable interval on one or other side, could always be done and thus increase the benefit obtained by surgery. In 12 advanced cases of Parkinsonism and in three cases of dyskinesia this procedure was followed, the results being quite gratifying. This practice of leaving midline screws in position and of marking the site of the lesion with an opaque steel ball in the operative procedure brought distinct advantages, since an additional lesion could then be created at the second or third operation with very little inconvenience to the patient and with considerable accuracy. The average operating-time for the second or third lesion was about 45 minutes. One young woman had five operations at intervals during a period of four years, with obvious improvement and no morbidity.

\section{Importance of Long-term Follow-up}

A point of particular interest and importance in this series was that the patients continued to improve for a long period after their second operation, sometimes for more than a year. Thus long-term follow-up studies were much more encouraging than short-term assessments, when a slight reduction in

TABLE II.-Neurosurgeon's Overall Assessment of Result of.Bilateral Operations in 75 Cases of Parkinsonism

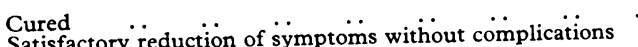

Satisfactory reduction of symptoms with

Total abolition of tremor and rigidity

Satisfactory reduction of tremor and rigidity

Satisfactory reduction of symptoms with

Total abolition of tremor and rigidity

Only slight reduction of symptoms on follow-up

$\begin{array}{ccc}\text { No. of Cases } \\ \ldots & 0 & \\ \ddot{4} & 42 & \\ 38 & & \\ \ddot{8} & 28 & \\ 20 & & \end{array}$


overall intellectual performance and initiative tended to cloud the early result and suggest a poor prognosis. Assessment of results on long-term follow-up is given in Tables II and III.

TABLE III.-Patients' and Relatives' Assessment of Usefulness of Bilateral Operation in 66 Cases of Parkinsonism (Minimum Follow-up Six Months)

\begin{tabular}{|c|c|c|c|c|c|}
\hline \multicolumn{2}{|c|}{ Improved Post-operatively } & \multicolumn{2}{|c|}{ Pre-operative } & \multicolumn{2}{|c|}{ Deteriorated Post-operatively } \\
\hline $\begin{array}{c}\text { To Higher } \\
\text { Grade }\end{array}$ & $\begin{array}{l}\text { In Same } \\
\text { Grade }\end{array}$ & Grade & $\begin{array}{l}\text { No. of } \\
\text { Cases }\end{array}$ & $\begin{array}{l}\text { In Same } \\
\text { Grade }\end{array}$ & $\begin{array}{l}\text { To Lower } \\
\text { Grade }\end{array}$ \\
\hline $\begin{array}{l}5 \\
6 \\
9\end{array}$ & $\begin{array}{c}2 \\
18 \\
11^{*} \\
4^{*}\end{array}$ & $\begin{array}{l}\mathbf{A} \\
\mathbf{B} \\
\mathbf{C} \\
\mathbf{D} \\
\mathbf{E}\end{array}$ & $\begin{array}{r}2 \\
27 \\
21 \\
16 \\
0\end{array}$ & $\begin{array}{l}2 \\
3 \\
2\end{array}$ & $\begin{array}{l}2 \\
1 \\
1\end{array}$ \\
\hline 20 & 35 & Total & 66 & 7 & 4 \\
\hline
\end{tabular}

* One patient has had two coronary attacks and three sustained fractures of the neck of femur and these have contributed to post-operative disability despite successful operation.

Classification of Grades: $A=$ Full working capacity. $B=$ Reduced working capacity. $C=$ Protected circumstances with minor home responsibilities. $D=A m b u l a n t$ but requiring some nursing care. $\mathrm{E}=$ Bedridden invalid requiring constant nursing care.

\section{Dyskinesias}

The other dyskinesias formed a small group and were concerned with the treatment of spasmodic torticollis, Wilson's disease, familial tremor, idiopathic intention tremor, choreoathetosis, and torsion dystonia. In our experience familial tremor, idiopathic intention tremor, choreoathetosis, and torsion dystonia responded satisfactorily to lesions in the ventro-lateral nucleus of the thalamus and adjacent capsule. The patient with Wilson's disease was extremely ill at the time of operation and responded poorly and eventually died some months later of bronchopneumonia. Spasmodic torticollis responded dramatically on occasion to lesions in the ventro-lateral nucleus of the thalamus, but, unfortunately, in our experience the neck movements soon recurred (our best period of complete relief was three weeks). However, long-term assessment of the results in this disease suggested that the intensity of the involuntary movements was reduced to a beneficial level.

\section{Indications and Contraindications for Bilateral Surgery}

The indications for operation in the second hemisphere are advancing symptoms and signs in the contralateral limbs when the first operation has been successful without significant sideeffects and with maintained improvement. We believe that disabling oculogyric crises may be an indication in selected cases for bilateral surgery. The main contraindications to bilateral surgery would seem to be definite deterioration of speech or intellectual and psychological status after the first operation. Age in itself is not a contraindication, although one would tend to be more careful after the age of 70 years in a patient with bilateral disease.

It has been suggested (Gillingham, 1961) that symptoms in Parkinsonism might be explained on the basis of the concept of a firing lesion. Increase of ipsilateral tremor after secondhemisphere surgery would tend to support such a hypothesis. It has been our clinical impression in analysing this series that in a number of cases the progress of the disease process has been halted, or at least considerably slowed, by the creation of stereotaxic lesions. However, a careful follow-up of unilateral and bilateral stereotaxic operations, as well as the study of a control series, would be necessary before offering this opinion as anything more definite than a clinical impression. With increasing experience and greater accuracy in the placement of lesions with depth micro-electrode recording (Gaze, Gillingham, Kalyanaraman, Porter, Donaldson, and Donaldson, 1964), it would appear that bilateral stereotaxic surgery is not hazardous. The ultimate duràtion and control of disability would seem to be dependent on accurate siting of the lesion which is large enough to be effective and yet not so large as to cause neurological, emotional, or intellectual deficit.

\section{Summary}

Seventy-five patients with Parkinsonism and eight with dyskinesias were treated with bilateral stereotaxic operations by the method of Guiot modified by Gillingham. The sites of lesions in the thalamus, capsule, and pallidum were verified by radiology and stereotaxic atlas charting and in some cases by biopsy, depth electrical recording, and necropsy.

Immediate post-operative mortality was nil. Major postoperative complications involving motor, sensory, or visual systems did not occur. Speech disturbances were the main disadvantages of bilateral procedures. Whenever there was slurring of speech or diminution of voice volume after the first procedure these defects tended to become worse after the second.

Rigidity and tremor were particularly amenable to surgery. Oculogyric crises were benefited in a large proportion of patients. Other symptoms were improved to a varying degree. Immediate assessment showed satisfactory improvement in 70 out of 75 cases. Long-term follow-up showed maintenance of improvement in 55 out of 66 cases.

From this study the main indications for bilateral surgery would appear to be advancing signs and symptoms in the contralateral limbs and persistence of oculogyric crises, especially when the first operation had been successful. The main contraindications would seem to be definite deterioration of speech or intellectual and psychological status after the first operation.

We wish to thank all the past and present members of staff of the Department of Surgical Neurology who have assisted in this work, in particular Dr. J. Laidlaw, Mr. J. J. Maccabe, Dr. A. F. J. Maloney, Dr. J. A. L. Naughton, Dr. A. N. da Rocha Melo, and Dr. W. S. Watson.

\section{REFERENCES}

Bertrand, C., and Martinez, N. (1962). Confin. neurol. (Basel), 22, 274. Broager, B., and Norhølm, T. (1961). f. Neurol. Neurosurg. Psychiat., 24, 297.

Cassinari, V., Pagni, C. A., Cabrini, G. P., and Pauli, P. (1963). Excerpta med. int. Congr. Ser., No. 60, 2nd Eur. Congr. Neurol. Surg., p. 118.

Cooper, I. S. (1961). Parkinsonism : Its Medical and Surgical Therapy, p. 118. Thomas, Springfield, Illinois, U.S.A.

- and Riklan, M. (1962). St. Barnabas Hosp. med. Bull., 1, 17.

Dierssen, G., Gioino, G. G., and Cooper, I. S. (1961). Neurology (Minneap.), 11, 894.

Donaldson, A. A., and Gillingham, F. J. (1960). Brit. F. Radiol., 33, 757

French, L. A., Story, J. L., Galicich, J. H., and Schultz, E. A. (1962). Confin. Neurol. (Basel), 22, 265.

Gaze, R. M., Gillingham, F. J., Kalyanaraman, S., Porter, R. W., Donaldson, A. A., and Donaldson, I. M. L. (1964). Micro-electrode Recordings from the Thalamus. In press.

Gillingham, F. J. (1961). Proc. roy. Soc. Med., 54, 375.

- (1962). Confin. Neurol. (Basel), 22, 385.

and Kalyanaraman, S. (1963). Excerpta med. int. Congr. Ser., No. 60,2 nd Eur. Congr. Neurol. Surg., p. 115.

No. (1964). The Surgical Treatment of Oculogyric Crises. To be published.

published. W. S., Donaldson, A. A., and Naughton, J. A. L. (1960). Brit. med. F., 2, 1395.

Gros, C., Serrats, F., Adib-Yazdi, and Parker, A. (1963). Excerpta med. int. Congr. Ser., No. 60, 2nd Eur. Congr. Neurol. Surg., p. 116.

Guiot, G. (1961). Rev. canad. Biol., 20, 395.

Hassler, R., Riechert, T., Mundinger, F., Umbach, W., and Ganglberger, J. A. (1960). Brain, 83, 337.

Krayenbühl, H., Siegfried, J., and Yasargil, M. G. (1963). Rev. neurol.,

108, 485. 429 .

Markham, C. H., and Rand, R. W. (1963). Arch. Neurol. (Chic.), 8, 621.

Meyers, R. (1963). F. Neurosurg., 20, 871.

Schaltenbrand, G., and Bailey, $\stackrel{P}{ }$. (1959). Introduction to Stereotaxis, with an Atlas of the Human Brain, vol. 2. Heinemann, London.

Spiegel, E. A., and Wycis, H. T. (1962a). Stereoencephalotomy, Part II, p. 328. Grune and Stratton, New York.

(1962b). Ibid., 276, p. 358.

Wycis, H. T. (1963). ₹. Neurosurg., $20,871$.

and Spiegel, E. A. (1958). In Pathogenesis and Treatment of Parkinsonism, edited by W. S. Fields, p. 294. Thomas, Springfield, Illinois, U.S.A. 